\title{
Dynamic Simulation of Hanford Tank Waste Remediation System
}

\author{
R. W. Harmsen \\ B. D. Zimmerman
}

Date Published

April 1996

To Be Presented at 1996 SCS Summer Computer Simulation Conference Portland, Oregon

July 21-25, 1996

To Be Published in Proceedings for the 1996 SCS Summer Computer Simulation Conference

Prepared for the U.S. Department of Energy Office of Environmental Restoration and Waste Management

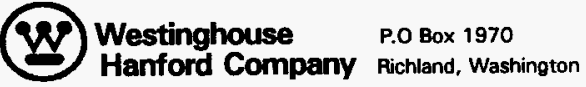

Hanford Operations and Engineering Contractor for the U.S. Department of Energy under Contract DE-ACO6-87RL10930

Coprion Linemen By soceptence of this ertide, the publicher and/or recipient ecknowledoes the U.S. Government'e right to retein a noneccluaive, roydty-freo license in and to eny copyright covering thie paper. 
LECAL DISCLAMER

This report was prepared as an account of work sponsored by an epency of the United States Government. Neither the United Stetes Government nor any agency thereof, nor any of their employess, not any of theit contractors, aubeontractors or their employes, mekes any warranty, express or implied, or mesumes any logal liebility or responabibitity for the accuracy, comploteness, or any third party's use of the results of auch use of any information, epparatus, product, or process disclosed, of represents that its use would not infringe privately owned rights. Reference herein to any specific commerciel product, process, or service by trade neme, tredemerk, menufecturor, of othorwiso, does not necesserily constitute or imply its ondorement, recommendation, or favoring by the Unitad States Government or any agency thereof or its contractors or subcentractors. The views and opinions of euthors expresead herein do not necesserily state or reflect those of the United States Govermment or any agency thereof.

This report hes been reproduced from the best available copy.

Printed in the United Sutes of Amarice

DISCLM-2.CHP (1-91) 


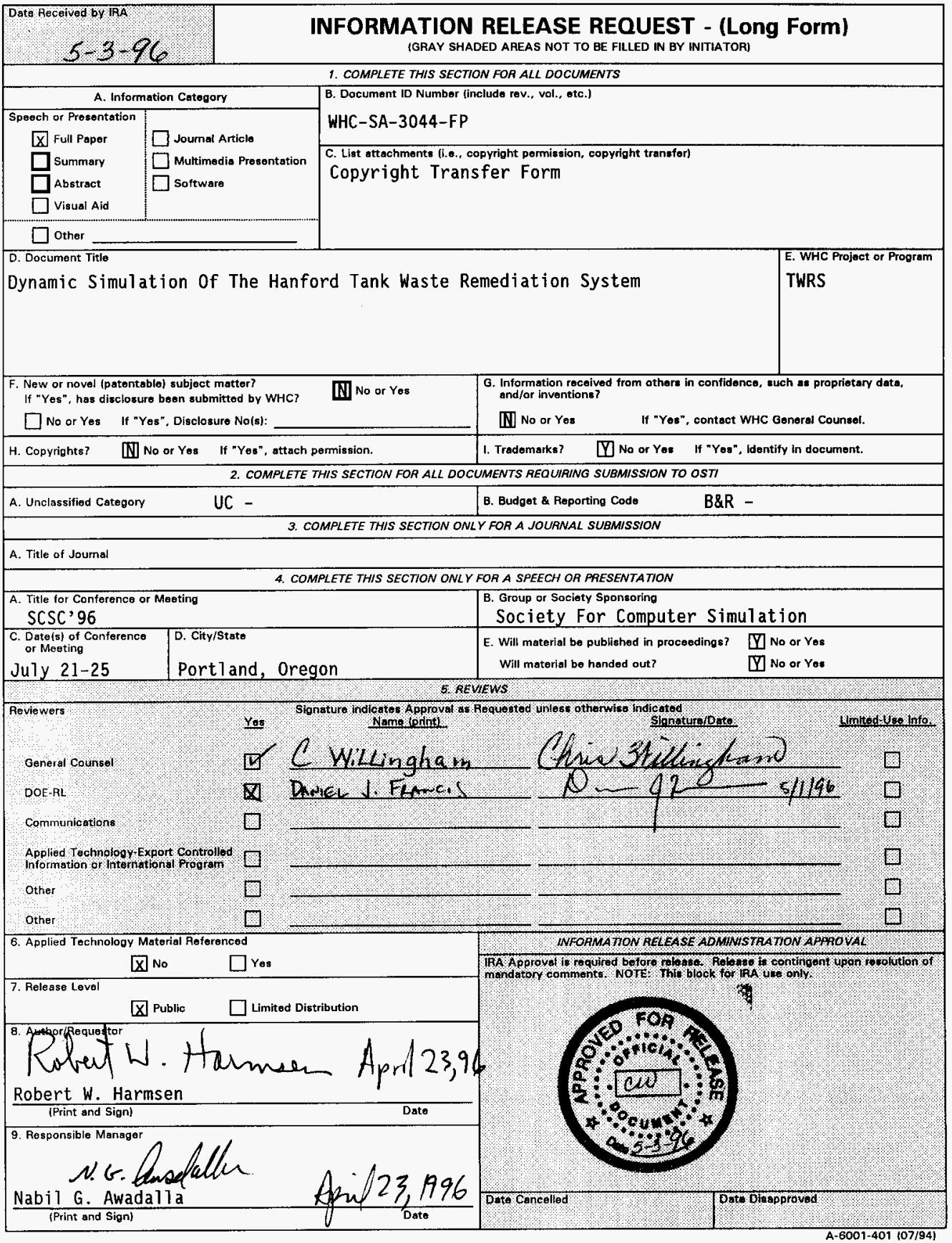


WHC-SA-3044-FP

Document io Number

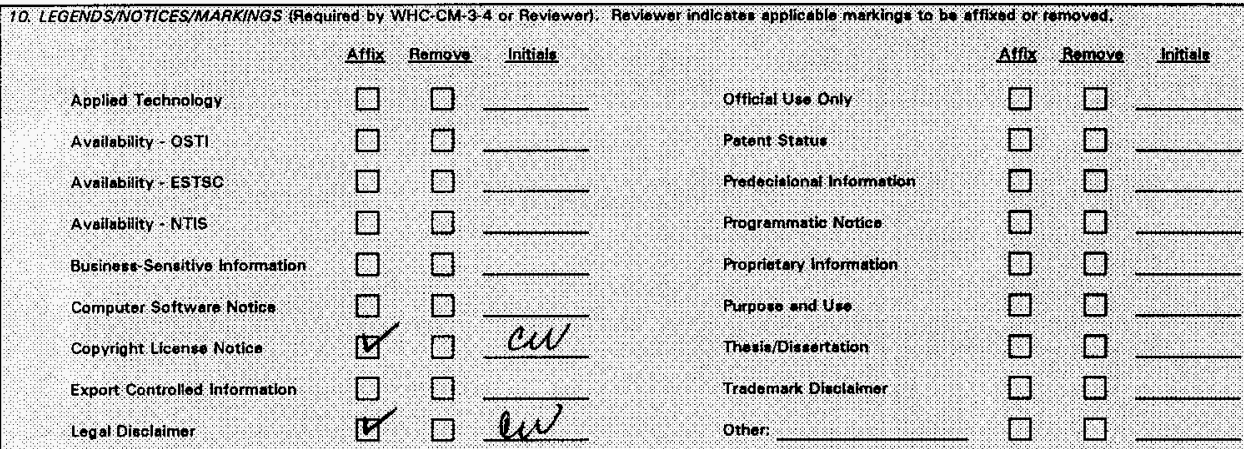

Limited Disclosura

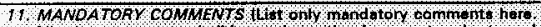
All other comments filil be nodo on the document ond returnod

to the euthor)

Roviowor (Prtut 8 ston

\begin{tabular}{|c|c|c|}
\hline 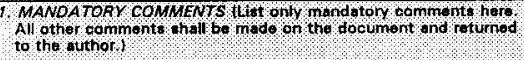 & proviowor & odo \\
\hline & & \\
\hline & & \\
\hline & & \\
\hline & & \\
\hline 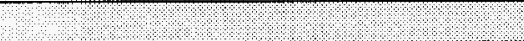 & & \\
\hline & & \\
\hline & & \\
\hline & & \\
\hline & & \\
\hline & & \\
\hline & & \\
\hline . & & \\
\hline 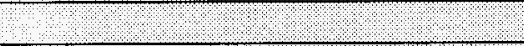 & & \\
\hline ? & & \\
\hline
\end{tabular}




\title{
DYNAMIC SIMULATION OF THE HANFORD TANK WASTE REMEDIATION SYSTEM
}

\author{
Robert W. Harmsen \\ Bruce D. Zimmerman \\ Westinghouse Hanford Company \\ Richland, Washington 99352
}

\section{KEY WORDS}

Chemical engineering, government, nuclear engineering, hybrid simulation, system dynamics.

\section{ABSTRACT}

Cleaning up and disposing of approximately 50 years of nuclear waste is the main mission at the U.S. Department of Energy's Hanford Nuclear Reservation, located in the southeastern part of the state of Washington. A major element of the total cleanup effort involves retrieving, processing, and disposing of radioactive and hazardous waste stored in 177 underground storage tanks. This effort, referred to as the Tank Waste Remediation System (TWRS), is expected to cost billions of dollars and take approximately 25 years to complete. Several computer simulations of this project are being created, focusing on both programmatic and detailed engineering issues. This paper describes one such simulation activity, using the ithink ${ }^{7 M} 1$ computer simulation software.

The ithink ${ }^{T M}$ simulation includes a representation of the complete TWRS cleanup system, from retrieval of waste through intermediate processing and final vitrification of waste for disposal. Major issues addressed to date by the simulation effort include the need for new underground storage tanks to support TWRS activities, and the estimated design capacities for various processing facilities that are required to support legally mandated program commitment dates. This paper discusses how the simulation was used to investigate these questions.

ithink ${ }^{\mathrm{MM}}$ is a registered trademark of High Performance Systems, Inc. of Hanover, New Hampshire.

\section{INTRODUCTION}

The Tank Waste Remediation System (TWRS) is responsible for retrieving radioactive and hazardous waste from 177 underground storage tanks, and processing and converting this waste to high-level radioactive waste (HLW) and low-level radioactive waste (LLW) glass for safe long-term storage. This clean up system must satisfy commitments among the U.S. Department of Energy, the U.S. Environmental Protection Agency (EPA), and the Washington State Department of Ecology (Ecology) as documented in the Hanford Federal Facility Agreement and Consent Order (Tri-Party Agreement) (Ecology et al. 1996).

The dynamic simulation includes retrieval of waste from tanks, sodium molarity and dilution adjustments, chemical pretreatment (or separations), evaporative concentration, in-process storage, and vitrification (conversion to glass). The model investigates proper facility sizing, as well as timing and sequencing of operational activities for multiple scenarios. Predetermined waste retrieval sequences from 149 single-shell tanks (SST), including special programs such as interim stabilization liquid pumping sequences (required for near-term removal of liquids from SSTs known or suspected to be leaking) are followed. Waste is received from the SSTs into 28 double-shell tanks (DST) for later retrieval for processing on an established schedute. The 28 DSTs are used for all short-term storage and process support needs. SSTs are used only for long-term storage.

Major constraints include various Tri-Party Agreement commitment dates for retrieval and processing, limited in-process storage space from the 28 DSTs, and resource commitments to the waste treatment privatization program. 
Privatization program constraints are the most recent. As part of the privatization program, demonstration glass plants are constructed and demonstrated by bidders from the private sector. Privatization strains the DST resource by using up to six DSTs to feed the demonstration HLW and LLW glass making processes. Although these demonstration plants provide early waste removal from the tank system, startup of the full-scale glass plants is delayed by several years.

\section{MODEL DESCRIPTION}

This application uses ithink $\mathrm{k}^{\mathrm{TM}}$ software dubbed "the visual thinking tool for the 90's." Processes are entered graphically using symbols. The associated equations are generated automatically. Rectangular "stocks" represent accumulations. Circular valves on "pipes" connected to stocks represent inflows and outflows. Circles represent mathematical or graphical converters. Stocks may

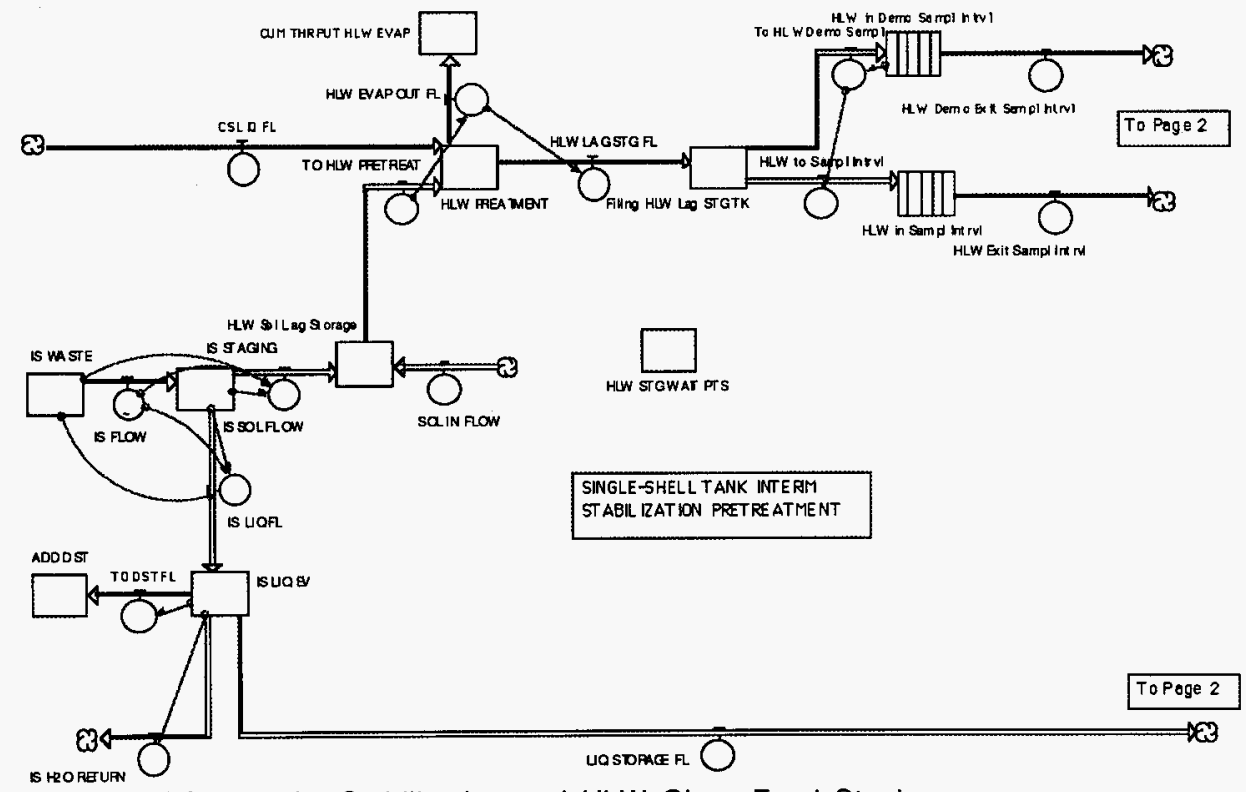

Figure 1 SST Interim Stabilization and HLW Glass Feed Staging also represent discrete processes such as ovens (with cook or process time), conveyors (with. transit time) or queues. Graphics are laid out in pages and sectors for modularity.

Figure 1 shows the first page of the model's forty-seven pages. Here SST interim stabilization waste liquids ("IS Waste") are retrieved from the SSTs and staged into the DSTs ("IS Staging") for concentration and LLW pretreatment. Retrieved and separated waste solids are placed into Solid Waste Storage ("HLW Sol Lag Storage"). Other solids also arrive at this lag storage location from a sludge wash process consisting of a series of in-tank settledecant cycles ("Sol In Flow"). The solids next undergo HLW pretreatment ("HLW Preatment") during which excess liquids are evaporated and cesium effluents from LLW pretreatment are added. Pretreated HLW fills a lag storage tank (feed tank for $H L W$ vitrification). When the fill criteria are satisfied, the HLW immediately enters a sampling

HW Dem o Ext Songl hinl To Page 2
SINGLE-SHELL TANK INTEAM ST ABIL IRAT KON PRETRE ATMENT 
interval ("HLW in Demo Sampl Intrvl" and "HLW in Sampl Intrul") typically 18 months long. Note that the conveyor modeling element is used to take a sequence of tanks through each tank's sampling interval.

Upon completing its sampling interval, a tank's contents immediately becomes suitable glass plant feed. Twelve lag storage tanks (DSTs) are dynamically allocated by the model for staging feed for the five glass plants. Figure 2 shows allocation of the tanks among the glass plants over the operating interval. The values include tanks allocated to privatization use. Curve 3 shows tanks containing LLW while Curve 4 shows tanks holding HLW. Only one feed tank is available at a time for each demonstration plant. Up to four HLW tanks may be allocated to LLW lag storage during lulls in HLW retrieval and processing.

A dominant parameter in the clean up system's behavior is the 18-month sampling delay before material is acceptable as glass plant feed. During this interval, government regulators verify that waste constituents are acceptable; and plant operators obtain the proper glass formers, or frit, to match the feed. The model uses a "just-in-time" approach to assigning a sampling tank for the HLW demonstration glass plant. This approach estimates future need time for a sampling tank based on current HLW glass plant backlog.

Control panels, created by the simulation programmer, aid in preparing parametric studies. The simulation software will generate sensitivity runs automatically, but the control panels help the operator locate parameters for analysis. The control panel for evaporators and pretreatment is shown in Figure 3. Specified evaporator exit molarities determine amount of concentration (hence water recycle and processing time) required. Sludge wash settling time is another dominant parameter that can be controlled by the operator but within limits allowed by natural laws. Plant capacities and rates are frequent subjects of parametric studies.

The sludge wash pretreatment process does reasonably well at separating LLW, such as slightly

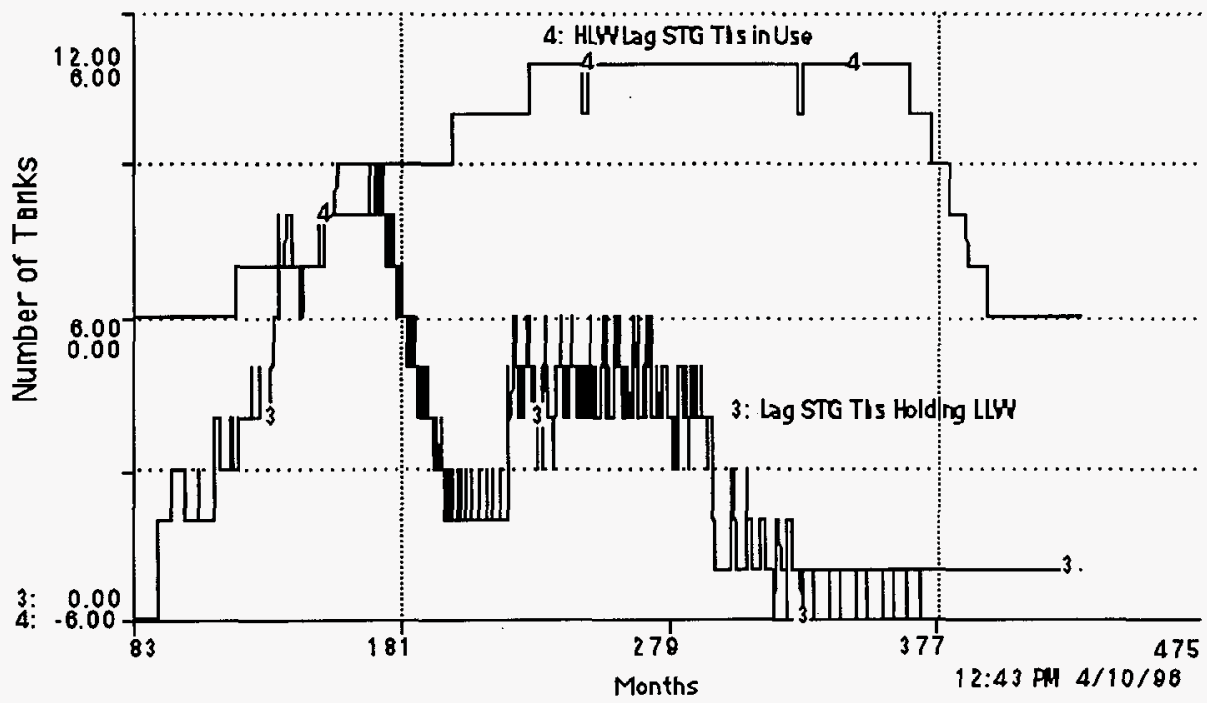

Figure 2 Tank Usage Vs. Time - - Three Operational Demonstration Glass Plants 


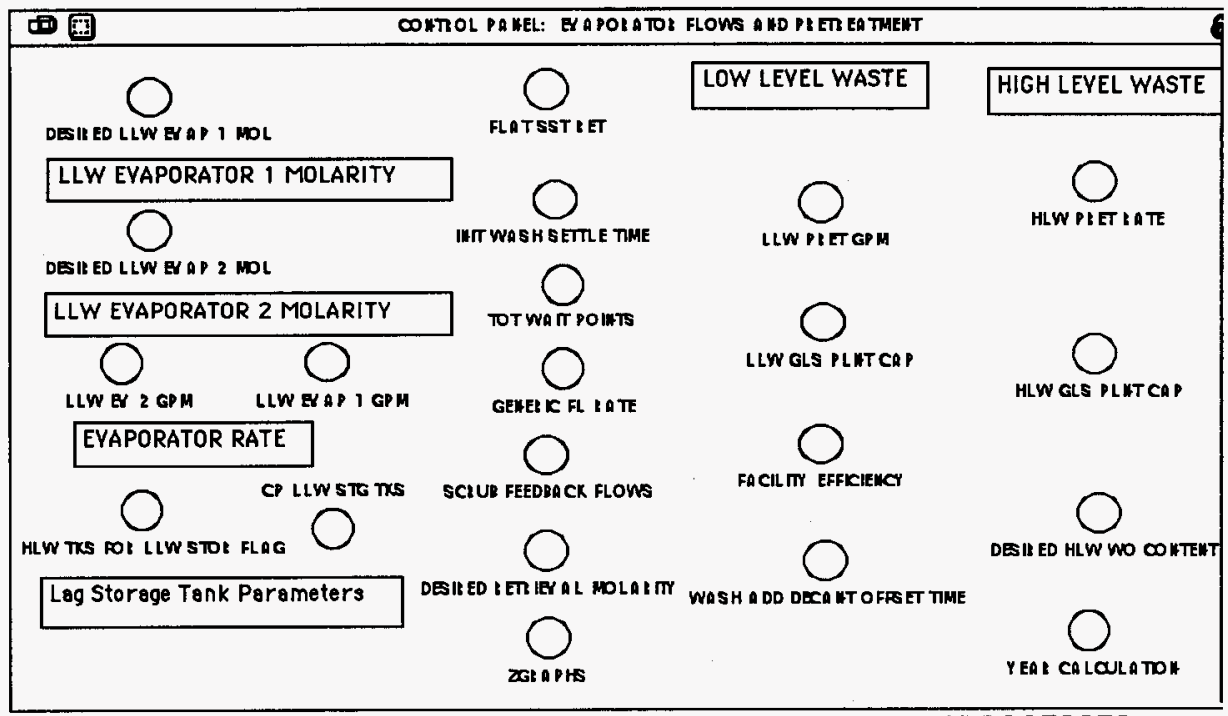

Figure 3 CONTROL PANEL FOR EVAPORATORS AND PRETREATMENT PROCESSES

radioactive sodium nitrate and aluminum ion, from HLW leaving behind insoluble strontium-90 and heavy metals in the solids. But the process generates huge volumes of LLW wash liquid. This in turn requires large evaporator capacities and large quantities of tanks to be allocated to LLW lag storage. The mode! rigorously accounts for each tank and for the hundreds of millions of liters of recycle water.

Validation of the model is performed by comparing material flows at key points with values on a static process flowsheet developed by process engineers. Also, internal mass balance checks are made during each simulation run.

\section{RESULTS}

Initiaily, the model was used to validate a decision to cancel a project for building six additional DSTs. The model showed that, if the rate of waste retrieval from the SSTs was fairly constant from 2004 (month 120) through 2018 (month 299), then the Tri-Party Agreement commitments could be met with no new underground tanks. Also, needed design capacities for new processing facilities were established, and optimal allocation of the DST lag storage resource was determined.

The advent of privatization meant that the model had to carefully stretch the scarce DST resource even further. The model explored the impacts of allocating DSTs to the private vendors against the benefits of early glass production. The impacts of multiple private vendor campaigns were assessed. Just-in-time use of tanks for regulatory agency sampling and evaluation was effectively utilized.

Initial (unvalidated) results from the model indicate that the TWRS can meet the commitments of the Tri-Party Agreement and privatization under the following conditions:

All 28 DSTs are committed to the TWRS clean up mission

*The HLW demonstration plant has no more than three one-million gallon campaigns and uses justin-time availability for the sampling tank 
*The LLW demonstration plants are operated before and after but not during the peak demand for LLW lag storage, 2008 through 2009 (months 156 through 184).

Figure 4 shows the result of applying these very reasonable conditions. In this figure, negative gallon values on the vertical axis represent a tank space surplus, positive values represent a tank space deficit. Beginning in December 2000 (83 months from the simulation start date), DST tank usage is declining until 2011 (month 213) because DST waste is being retrieved, concentrated, and converted to glass. Then, DST usage rapidly increased due to maximum rate SST retrieval. The DST surplus reaches zero in 2017 (month 279). This is significant because a DST deficit would mean that the system can not operate. The system then steadily works off the accumulated glass plant feed. The final glass log is completed in 2026 (month 386).

Additional model programming and verification work is underway.

\section{REFERENCES}

Ecology, EPA, and DOE, 1996, Hanford Federal Facility Agreement and Consent Order, 2 vols., as amended, Washington State Department of Ecology, U.S. Environmental Protection Agency, and U.S. Department of Energy, Olympia, Washington.

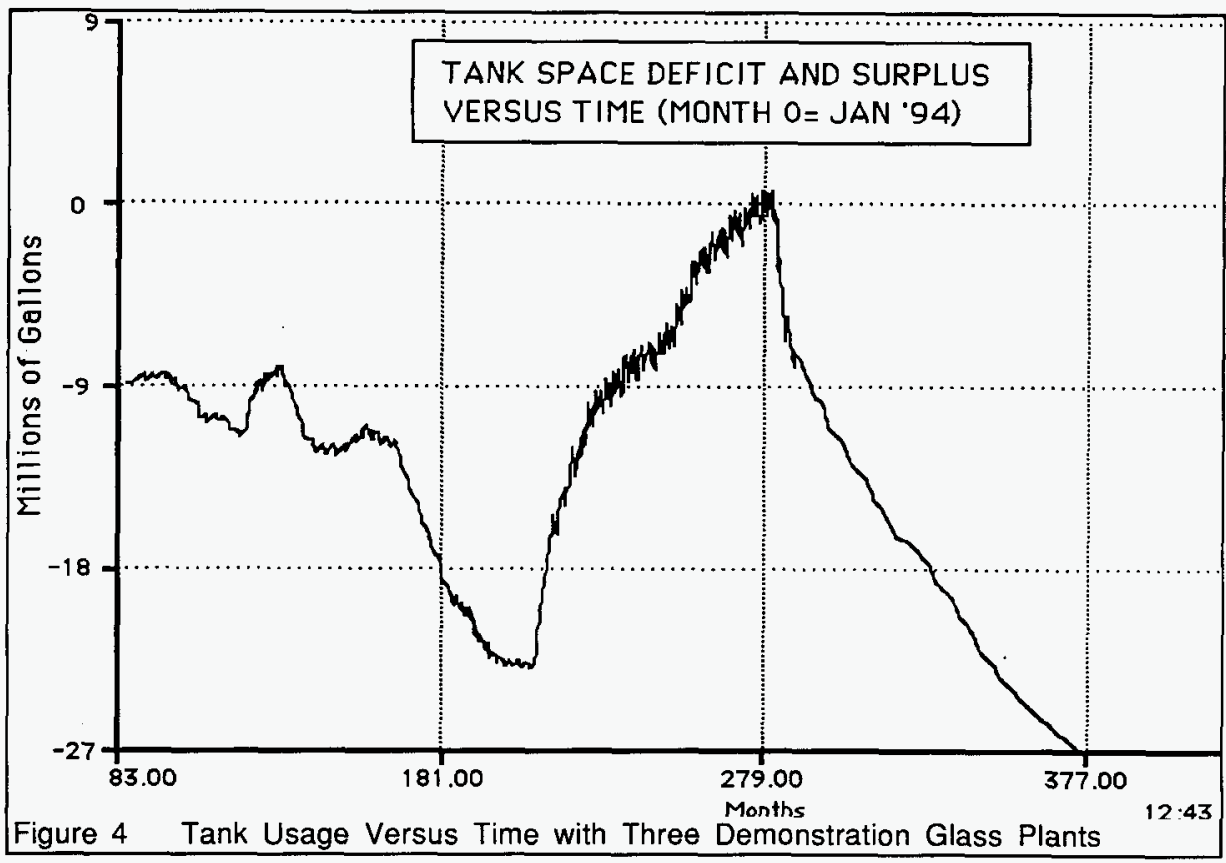




\section{DISTRIBUTION}

Number of copies

\section{ONSITE}

1

\section{U.S. Department of Energy.} Richland Operations Office

D. J. Francis

K6-51

1

Pacific Northwest National Laboratory

W. G. Richmond

H6-51

21 Westinghouse Hanford Company
N. G. Awadalla
H6-35
P. J. Certa
H5-61
B. C. Gneiting
H6-35
C. E. Grenard
H5-61
R. W. Harmsen (5)
H6-35
B. J. Knutson
H6-35
A. K. Lee
H6-33
R. M. Orme
H5-27
D. L. Penwell
H5-27
J. D. Thomson
H6-35
B. D. Zimmerman (5)
H6-35
Central Files
A3-88
Document Processing Center
A3-94 